\title{
CORPOS AUTISTAS: PERCEPTOS E MOVIMENTOS DE PROFESSORES QUE ENSINAM CIENCIAS
}

\author{
AUTISTIC BODIES: PERCEPTIONS AND MOVEMENTS \\ OF TEACHERS TEACHING SCIENCES
}

\section{Alexandre Luiz Polizel ${ }^{1}$ Moises Alves de Oliveira ${ }^{2}$}

\begin{abstract}
RESUMO: Objetiva-se levantar considerações acerca dos perceptos e deslocamentos nas movimentações educacionais de professores que lecionam ciências em seus encontros com corpos autistas em sala de aula. Para isto, utiliza-se de pesquisa qualitativa de cunho interpretativo, utilizando questionário online contento quatro questões dissertativas, divulgado em dois grupos da rede social Facebook: "Professores PSS Paraná" e "Pibid". Divulgação realizada semanalmente nos meses de dezembro de 2017 e janeiro de 2018, direcionado a professores que tiveram experiências com corpos localizados em Transtorno do Espectro Autista (TEA) e que ensinassem ciências. Para análise dos questionários considerou-se o discurso, apresentando a inspiração nas contribuições de Michel Foucault. A apresentação dos resultados deu-se em dois eixos: a) Os perceptos de professores que ensinam ciências sobre corpos em TEA e, b) movimentações educacionais de professores que lecionam ciências no contato com corpos em TEA. Evidenciou-se que os professores identificavam os corpos em TEA como: 1) uma ausência, dificuldade ou patologia em relação a um quadro de normalidade, 2) um excesso de sensibilidade nas relações em relação a um quadro de normalidade, 3) um modo de existir outro e 4) um corpo em TEA acompanhado de um corpo de uma professora de apoio. Vê-se também movimentações educacionais a fim de potencializar o processo educativo-disciplinatório, de modo a incluir os corpos em TEA no processo de normalização, movimentos esses que envolvem um olhar de diagnose constante na própria prática docente, envolvendo busca de saberes, adaptações espaciais e um redirecionamento do olhar.

Palavras-chave: Ensino de Ciências. Transtorno do Espectro Autista. Disciplina. Biopolítica. Perceptos.
\end{abstract}

\begin{abstract}
$\boldsymbol{A B S T R A C T : ~ T h e ~ o b j e c t i v e ~ i s ~ t o ~ c o n s i d e r ~ c o n s i d e r a t i o n s ~ a b o u t ~ t h e ~ p e r c e p t i o n s ~ a n d ~ d i s l o c a t i o n s ~ i n ~ t h e ~}$ educational movements of teachers who teach science in their meetings with autistic bodies in the classroom. For this, a qualitative research with an interpretive character was used, using an online questionnaire that was filled with four essay questions, published in two groups of the social network. Facebook: "Professors PSS Paraná" and "Pibid". Disclosure held weekly in the months of December 2017 and January 2018, aimed at teachers who have had experiences with bodies located in Autism Spectrum Disorder (TEA) and that teach science. For the analysis of the questionnaires the discourse was considered, presenting the
\end{abstract}

\footnotetext{
${ }^{1}$ Mestrando no Programa de Pós-graduação em Ensino de Ciências e Educação Matemática pela Universidade Estadual de Londrina.

http:// orcid.org/0000-0001-6397-306X

2 Professor no Departamento de Química da Universidade Estadual de Londrina. Orientador no Programa de Pós-graduação em Ensino de Ciências e Educação Matemática pela Universidade Estadual de Londrina. Coordenador do Grupo de Estudos Culturais das Ciências e das Educações

http://orcid.org/0000-0003-3020-6459
} 
inspiration in the contributions of Michel Foucault. The results were presented in two axes: a) The perceptions of teachers who teach science about bodies in ASD and, b) the educational movements of teachers who teach sciences in contact with bodies in ASD. It was evidenced that the teachers identified the bodies in TE $A$ as: 1) an absence, difficulty or pathology in relation to a normality frame, 2) an excess of sensitivity in the relations in relation to a normality frame, 3) a way of there is another and 4) a body in TE $A$ accompanied by a body of a support teacher. It is also seen educational movements in order to potentialize the educational-disciplinary process, in order to include the bodies in TE $A$ in the normalization process, movements that involve a constant diagnosis in the teaching practice itself, involving the search for knowledge, spatial adaptations and a redirection of the look.

Keywords: Science Teaching. Autistic Spectrum Disorder, Discipline. Biopolitic. Percept.

\section{NOTAS INTRODUTÓRIAS}

Transtorno... Aquilo que gera incômodo a outrem ou a uma ordem vigente. São os transtornos que nos movimentaram a pensar este manuscrito, que teve por objetivo levantar considerações acerca dos perceptos ${ }^{3}$ e deslocamentos nas movimentações educacionais produzidos por professores de ciências, quando em contato com corpos autistas no espaço de suas salas de aula. Voltamo-nos, então, a pensar de modos "transtornados".

Seguimos as teorizações de Michel Foucault (1972), por considerarmos que os olhares em relação aos "transtornos" são localizáveis no interior da história-contingência e das relações estabelecidas entre poder e saber. Consideramos também que os discursos sobre os modos de existir e as identificações ${ }^{4}$ mentais como produções epistêmicas, ou seja, pertencem ao conjunto de relações discursivas, que em um espaço-tempo, produzem uma imagem epistemológica, não fechada, indefinidamente móvel (cf. Foucault, 2002). É a episteme que acolhe, nos encontros dos discursos, uma produção científica a ser (re)conhecida, bem como dá a esta a outorga de legislar modos de vida, constituindo um discurso de verdade. Para Foucault:

Por episteme entende-se, na verdade, o conjunto das relações que podem unir, em uma dada época, as práticas discursivas que dão lugar a figuras epistemológicas, a ciências, eventualmente a sistemas formalizados; o modo segundo o qual, em cada uma dessas formações discursivas, se situam e se realizam as passagens à epistemologização, à cientificidade, à formalização; a repetição desses limiares que podem coincidir, ser subordinados uns aos outros, ou estarem defasados no tempo; as relações laterais que podem existir entre figuras epistemológicas ou ciências, na medida em que se prendam a práticas discursivas vizinhas mais distintas. A episteme não é uma forma de conhecimento, ou um tipo de racionalidade que, atravessando as ciências mais diversas, manifestaria a unidade soberana de um sujeito, de um espírito ou de uma época; é o conjunto das relações que podem ser descobertas para uma época dada, entre as ciências, quando estas são analisadas no nível das regularidades discursivas (FOUCAULT, 2002, p. 217).

A partir deste referencial teórico, pensar em "Transtornos do Espectro Autista” (TEA) é caracterizar, em um conjunto de movimentos, de discursos, de intencionalidades, de saberes e

\footnotetext{
3 Perceptos consistem Segundo Gilles Deleuze (2004) como pacotes de sensações e de relações, esses pacotes são mantidos nos corpos daqueles que vivenciaram tal sensação. O perspecto nesse sentido diferencia-se da percepção, visto que a percepção busca uma organização racionalizada e categórica das sensações vividas. O percepto busca uma expressão sensível das sensações e das relações experiênciadas.

"Utilizamos aqui o termo "identificações", considerando esta como um processo de localizar determinada característica em um quadro de referências que estabelece a suposição de existência de uma identidade fixa, cristalizada e, desta forma, estabelece identifica sujeitos com base em determinadas características (cf. FOUCAULT, 2016; cf. NIETZSCHE, 1974).
}

PRACS: Revista Eletrônica de Humanidades do Curso de Ciências Sociais da UNIFAP https://periodicos.unifap.br/index.php/pracs ISSN 1984-4352 Macapá, v. 12, n. 1, p. 23-38, jan./jun. 2019 
poderes, que se articulam e flertam entre si em um dado espaço-tempo, a produção de efeitos de verdade que regem os modos de vida, à medida que produzem quadros de referência. Esses quadros de referência alinham-se ao que Foucault $(2016 ; 2015 ; 1994)$ trata como "regimes de verdade", ou seja, aos modos de ler o mundo e as "experiencialidades" 5 , nas tramas do saberpoder estão emaranhadas também noções de verdade. Estas, por sua vez, naturalizam valorações que não são naturais e estabelecem dicotomias, tais como: certo e errado, normal e anormal, saúde e doença. Assim, se tratamos algo como "Transtorno do Espectro Autista" (TEA) e se enquadramos sujeitos nesta posição, é por localizá-los, por produzi-los como uma margem, na mesma medida em que se produz, demarca uma noção de normalidade.

Este regime de verdade que institui categoricamente determinados modos de ser como TEA consiste em uma invenção recente, emaranhada nos saberes-poderes, e que se fundam sob o discurso médico-higienista: uma ciência médica, uma ciência biológica, que produz corpos à medida que os disseca e descreve-os em um saber valorado e enrijecido. O próprio processo descritivo realizado pelo poder médico-legislativo que institui o dito autismo, instaura-se via produção de um guia de classificação diagnóstica, produzido, apenas em 2013, com o advento do Manual Diagnóstico e Estatístico de transtornos mentais 5 (DSM 5).

O transtorno do espectro autista caracteriza-se por déficits persistentes na comunicação social e na interação social em múltiplos contextos, incluindo déficits na reciprocidade social, em comportamentos não verbais de comunicação usados para interação social e em habilidades para desenvolver, manter e compreender relacionamentos. Além dos déficits na comunicação social, o diagnóstico do transtorno do espectro autista requer a presença de padrões restritos e repetitivos de comportamento, interesses ou atividades (AMERICAN PSYCHIATRIC ASSOCIATION, 2014, p. 31).

Assim, ao voltar olhares às discursividades produtoras do TEA, evidencia-se que estas se enquadram no campo da saúde mental. Foucault, em seu ensaio sobre a História da Loucura (1972), desenvolve explanações acerca da produção dos saberes-poderes sobre a "saúde mental", sobre a insanidade, sobre um personagem, sobre um modo de ser e estar localizado nas experiencialidades, utilizando a primeira e última carta do Tarot' 6 O louco ${ }^{7}$. A "loucura", se podemos chamar assim, por ser uma terminologia que se institui na Modernidade, é vista de modos diversificados nas diferentes relações de espaço-tempo. $\mathrm{Na}$ Antiguidade era exaltada nas relações de adivinhação e contatos com o divino. Na Idade Média relacionada com o

\footnotetext{
${ }^{5}$ Note-se que toda atribuição de significados e representações ao vivido são mediadas pela experiência. Cada identidade que experimenta a realidade tem características singulares. Às similitudes das experiências de acordo com suas identificações, dá-se o nome de "experiêncialidades".

${ }^{6}$ Tarot consiste em um jogo de cartas de origem francesa. Aqui utilizo o Tarot como um termo metafórico a fim de apresentar que a figura do louco, como pontuado por Foucault (1972) surge de jogos de saberes-poderes que atribuem para esta característica identitária distintas posições de sujeitos, sentidos e significações.

7 Destacamos aqui a utilização do "louco" como um personagem conceitual, metafórico. O Louco em Foucault (1972) é aquele que opera como dissidente em relação a um regime de verdade que institui a normalidade de viver segundo certas práticas mentais, e, no curso histórico, passa por um processo de regulação discursiva. Na Idade Média os loucos estão sujeitos ao mecanismo de exclusão, via expulsão da verdade. Na Modernidade, passam pelo mecanismo discursivo da segregação, sendo designados certos locais especiais para sua permanência, os hospitais psiquiátricos. Nota-se que, atualmente, existe uma preocupação e um investimento para a inclusão destes corpos antes segregados, o que também atravessa os corpos TEA. Neste sentido, a aproximação realizada entre os "transtornos" e a loucura, consiste na localização destes corpos no esquadro dos regimes de verdade, instaurados no discurso médico-biológico, médico-legal, como corpos dissidentes de uma norma, mas passíveis de uma normalização via inclusão. Neste sentido, o campo educacional é catalisado, e busca modos de incluir os corpos TEA via adequação de práticas educativas.
} 
aspecto de erro e de falta de razão. E, na Modernidade, como uma ameaça contagiosa à razão. Todos estes discursos que atravessam a contemporaneidade, reverberando-se e rarefazendose, deslocando as dinâmicas nas eleições dos modos de existir e de onde existências serão posicionadas.

Ressaltamos que a ideia de ameaça ao olhar os "transtornos mentais" na Modernidade funda instituições de confinamento que atuam sobre os corpos, os produzem, os disciplinam. Espaços que alocam os corpos que fogem do que é considerado como "normalidade" mental em determinada época, consideração esta reforçada pela existência de instituições, tais como: os hospícios, os manicômios, os hospitais psiquiátricos, as casas de recuperação são construídos. A produção destas instituições e a alocação de corpos nestes espaços agem sob o controle da circulação destes corpos, de seus saberes-poderes, da inquietação que estes geram na ordem.

Contudo, ressalta-se que nenhum anseio por ordem elimina totalmente sua fonte de inquietação. Os regimes de verdade, assim, utilizam a produção de uma valoração de "anormalidade" para manter-se no status de "normalidade". Assim, as instituições de confinamento são espaços modelos, que confinam corpos para discipliná-los, controlando seus espaços, tempos, saberes, as características biológicas de seus corpos via administração de fármacos, bem como suas representações. É assim, na relação corpo-disciplinamento, que serão julgados os corpos que se mantêm confinados e os corpos que poderão novamente transitar (cf. FOUCAULT, 2015; 1994).

Destacamos que os espaços disciplinares são espaços de controle, de produção de corpos, de manutenção da vida. Manutenção da vida na medida em que o modelo de sociedade, a qual Foucault $(2015$; 1994) trata como sociedade disciplinar, e na qual um biopoder, ou seja, os poderes que atuam sobre as vidas, sobre os modos de existência, tornam-se regente. O biopoder, conceptualizado por Foucault, demarca o investimento de tecnologia de poder disciplinar que pode ser compreendida de duas formas: como a) um investimento disciplinar sob um corpo-população, que provém de uma visão universal do corpo como membro de uma espécie e, desta forma deve ter sua vida preservada e normalizada, ou b) como um investimento disciplinar sob um corpo-indivíduo, de modo que o corpo do indivíduo é visto como máquina, com investimentos contínuos para que ele se torne disciplinado, produzindo o melhor funcionamento deste corpo. Assim, a disciplina consiste em uma tecnologia de poder que é "[...] centrada no corpo, produz efeitos individualizantes, manipula o corpo como foco de forças que é preciso tornar úteis e dóceis ao mesmo tempo" (FOUCAULT, 1999, p. 297). O investimento do biopoder, no curso da sociedade disciplinar, está em manter vivos e potencializar os modos de existir considerados "normais".

Destaca-se que a contemporaneidade mantém tais instituições normalizadoras, sejam como estruturas físicas, sejam como simbólicas, de modo que as práticas disciplinares encontram seu ápice de interiorização, não precisando mais de paredes de concreto, pois as próprias escolas se destacam como uma destas instituições disciplinadoras (cf. FOUCAULT, 2016; 1994). Deste modo, voltamos nosso olhar às investidas dos biopoderes, na produção da identificação de sujeitos na posição dos "Transtornos do Espectro Autista" e, assim, na inclusão destes em espaços de produção social, cultural, econômico, no qual destaco o espaço escolar.

O espaço escolar valida que determinado corpo se encontra engendrado ao funcionamento de uma suposta "normalidade" da espécie: corpos produtivos economicamente, dóceis politicamente (cf. FOUCAULT, 1994). Investidas são feitas para a inserção daqueles que antes não transitavam no meio escolar, para que passem por tal espaço de disciplinamento: vigora-se o

PRACS: Revista Eletrônica de Humanidades do Curso de Ciências Sociais da UNIFAP https://periodicos.unifap.br/index.php/pracs ISSN 1984-4352 Macapá, v. 12, n. 1, p. 23-38, jan./jun. 2019 
dispositivo da inclusão. Os dispositivos são

[...] um conjunto decididamente heterogêneo que engloba discursos, instituições, organizações arquitetônicas, decisões regulamentares, leis, medidas administrativas, enunciados científicos, proposições filosóficas, morais, filantrópicas. Em suma, o dito e o não dito são elementos do dispositivo. O dispositivo é a rede que se pode estabelecer entre esses elementos (FOUCAULT, 2016, p. 364).

Destarte, instaurado o dispositivo de inclusão, corpos enquadrados com TEA passam a ser inseridos no espaço educacional, que sofre adaptações, deslocamentos, e nos inquieta, levando-nos ao questionamento: "Como educadores que ensinam ciências, ao se depararem com corpos autistas em sala de aula, percebem (ou não) estes corpos e de que modos estes encontros deslocam suas movimentações de intuito educacional?”. Esta inquietação guia este manuscrito, que se encontra organizado em: Movimentações metodológicas; Percetos mediados por professores que ensinam ciências; e Disciplinamento dos corpos e modificações de condutas.

\section{MOVIMENTAÇÕES METODOLÓGICAS}

A fim de investigar "Como educadores que ensinam ciências, ao se depararem com corpos autistas em sala de aula, percebem (ou não) estes corpos e de que modos estes encontros deslocam suas movimentações de intuito educacional?", inclinamo-nos à pesquisa qualitativa, de cunho interpretativo, visando olhar para as singularidades, as contingências e para os rastros de subjetivações circulantes, que deixam sua ranhura nas superfícies. Sob tal óptica, não temos por objetivo uma amplitude numérica de expressividade de resposta, mas antes visamos destacar a qualidade interpretativa dos perceptos que emergem das análises.

Para isso, foi confeccionado um questionário disponibilizado via online 8 aos sujeitos desta pesquisa, os professores de ciências do Estado do Paraná. O questionário mostrava-se composto de um "Termo de Consentimento Livre Esclarecido" e de quatro questões dissertativas, sendo elas:

- Questão 1 - Fale sobre você, sobre sua história de vida: nome, idade, disciplina que ministra, formação, cidade onde atua, tempo de atuação, se participa de algum projeto.

- Questão 2 - De acordo com sua história de vida o que você entende por autismo? O que significa uma pessoa ser/estar com transtorno do espectro autista? Teve um aluno Autista? Conte um ou dois acontecimentos de sua história de vida que explane o ser autista na escolar

- Questão 3 - Segundo suas vivências descreva um acontecimento que represente como foi sua experiência com um estudante autista, o primeiro contato, as relações e o uso do espaço escolar.

- Questão 4 - Apresente um breve relato de experiências uma das intervenções/trabalhos pedagógicos executados na turma onde este estudante encontrava-se inserido (apresente a temática, suas sensações, os obstáculos e como foram suas ações como educador).

${ }^{8}$ Questionário disponível no endereço eletrônico: < https://goo.gl/forms/mEzvPhRNFo6EEzxI2>. 
Demarca-se que a questão 1 tinha por objetivo perfilar a relação que o educador mantinha com sua docência. Os questionamentos 2 e 3 visavam direcionar o olhar para quais foram os perceptos dos educadores referentes aos corpos TEA. E que a questão 4 visava analisar como os educadores deslocavam suas práticas pedagógicas com o intuito de inclusão dos corpos TEA.

Optamos pela aplicação online de questionário estruturado, reconhecendo que este instrumental é de fácil produção, poucos gastos, garante anonimato nas respostas, não expõe pesquisador a opiniões pessoais, dispensa um profissional presente fisicamente para a coleta de dados e, finalmente, proporciona um amplo alcance de divulgação transpondo fronteiras físicas. Todavia, reconhecemos que o mesmo apresenta também limitações, tais como: requerer pessoas dispostas a acessa-lo, restringir participação daqueles que apresentam alfabetização digital, impedir aprofundamentos via auxílio no entendimento das perguntas, impedir o conhecimento das circunstâncias no momento de resposta dos questionários, não oferecer garantia de devolutiva, apresentar alta probabilidade de não ser respondido (caso apresente muitas questões), apesar de ser respondido por pessoas interessadas e envolvidas com práticas de pesquisa (cf. CHAER; DINIZ; RIBEIRO, 2011).

Após produzido o questionário, o mesmo foi divulgado em dois grupos da rede social Facebook, sendo eles: Professores PSS do Paraná e Pibid ${ }^{10}$. O grupo Professores PSS do Paraná, consiste em um grupo com 42.064 membros, sendo estes em situação atual como professores em regime de contrato temporário, via processo seletivo simplificado no estado do Paraná, espaço virtual criado com objetivo de divulgação de cursos, editais, bibliografias, pesquisas técnico-científicas e diálogos gerais. O grupo Pibid tem em sua composição 24.812 membros, sendo estes (ex)participantes do Programa Institucional de Bolsas de Iniciação à Docência, programa de âmbito nacional que tem por objetivo o incentivo de licenciandos ao exercício de Docência.

Os grupos foram escolhidos sob o critério de conveniência, visto que os pesquisadores são membros de ambos os grupos, conhecem a dinâmica neste (ciber)espaço e (re)conhece o grupo como um espaço colaborativo para a socialização das experiencialidades e práticas educacionais. Assim, reconheceram estes espaços como potentes divulgadores do questionário, esperando retornos significativos nestes. O questionário foi (re)publicado em ambos os grupos semanalmente, durante o mês de dezembro de 2017 e janeiro de 2018. Na divulgação do questionário, foi utilizado o excerto desenvolvido pelos próprios autores:

Pessoal, sei que estamos em um momento complexo. Todos estamos lutando pela educação pública - nas ruas, nas produções, na pressão ao legislativo. Acredito que como eu muitos no grupo tem grande apreço pelo ser professor. Assim, gostaria de pedir encarecidamente se podiam me auxiliar, compartilhando suas histórias de vida. Meu enfoque atual, em um projeto de pesquisa em desenvolvimento como parte constituinte da realização de um curso de pós-graduação lato sensu em "Transtornos do Espectro Autista \& Transtornos Globais do Desenvolvimento" é registrar perceptos e movimentos pedagógicos de professores que tiveram contato com alunos com autismo em suas práticas. Criei o questionário online para facilitar, de título "Autismos e as Educações", contendo quatro questões dissertativas. Vou ficar muito feliz se

9 O acesso ao grupo pode ser dado por meio do endereço eletrônico: < https://www.facebook.com/groups/ $196059480460904 />$. Acesso em 5 de fevereiro de 2018

$10 \mathrm{O}$ acesso ao grupo pode ser dado por meio do endereço eletrônico: < https://www.facebook.com/groups/ $1600686786872263 />$. Acesso em 5 de fevereiro de 2018 
quem viveu esta experiência pudesse partilha-la e colaborar com o estudo.

Demarca-se que as características apontadas já na divulgação do endereço eletrônico que dá acesso ao questionário, bem como no "Termo de Consentimento Livre Esclarecido", a informação de que os participantes deveriam ter atuado na prática docente em salas em que seus corpos se depararam com corpos de estudantes identificados com "Transtorno do Espectro Autista". Nove pessoas responderam o questionário. A partir desta resposta, foi elencada outra característica para delineação do corpus de análise: o enfoque em professores que ensinassem "ciências"11. Assim, oito sujeitos constituíram o corpus desta investigação.

O enfoque em professores que ensinam ciências deu-se devido: a) ao interesse de área manifestado pelos pesquisadores; b) à relação direta dos professores que ensinam ciências e as discursividades médico-biológicas, o que instiga nosso interesse a como os perceptos acerca dos corpos TEA são negociados nas representações destes; e, finalmente, c) devido à tímida produção científica relacionando Educação inclusiva e ensino de ciências, como evidenciado por Fabiana Guntzel (GUNTZEL; OLIVA; KRAUSE, 2016) e colaboradores em levantamento nos anais dos "Encontros Nacionais de Ensino de Ciências".

As respostas dadas foram investigadas por meio de análise de discurso, sob inspiração no referencial teórico foucautiano $(2016 ; 2015 ; 2002$; 1999; 1994; 1972; 1967), visto a produtividade deste referencial no que toca a analítica do poder disciplinar e os processos de normalização em corpos TEA, mediados pelos perceptos docentes. É neste tocante que analisamos os discursos, os enunciados e as enunciações, recusando formas unívocas e de compreensões rápidas e fáceis, na ideia de que o discurso é um conjunto de signos e de sentidos apenas. Assim, volta-se ao esforço de olhar para o discurso, a fim de procurar o oculto, de buscar rastros de como a enunciação torna-se enunciados e formam epistemes. Um caminho sugerido pela teórica de referencial foucaultiano, Rosa Maria Bueno Fischer (2001), que nos faz observar o discurso como um conjunto de enunciados e o próprio enunciado como função, considerando princípios de: a) diferenciação, via um quadro de referências que permite localizar o enunciado; b) posição ocupada, geralmente interligado a um sujeito; c) campos associados, que se relaciona e coexiste com outros enunciados; d) materialidade específica, localizada em escritas, gravuras, passividade de repetição e de criação de enunciados outros, envolto também em técnicas, práticas e relações sociais que garantem aos discursos-enunciados uma materialidade. Eixos estes que serão considerados na leitura dos enunciados-enunciações. Enunciações que serão apresentadas e explanadas individualmente ou no encontrar de pontos de similitudes entre o registro dos sujeitos.

A análise organizou-se em dois movimentos: a) Quais os perceptos mediados por professores que ensinam ciências no encontro com os corpos TEA; b) Que modificações são realizadas nas práticas docentes com intuito de inclusão. Estes movimentos foram utilizados como fios condutores para análise, visando capturar pontos de similitudes nas narrativas dos sujeitos participantes. As similitudes foram nomeadas e agrupadas de modo emergente, sem ordenações a prori.

Os sujeitos tiveram seus nomes codificados via atribuição da letra "S" (de sujeitos) e

11 Delineamos "professores que ensinassem ciências" considerando que as ciências são organizadas como um campo de saberes que se configura como uma disciplina escolar que pode ser ministrada por múltiplas formações. A disciplina escolar de ciências pode ser ministrada por professores formados nas licenciaturas em ciências biológicas, ciências naturais, ciências físicas e química, no caso dos anos finais do ensino fundamental, e por pedagogos, no caso dos anos iniciais do ensino fundamental. 
número equivalente a ordem de resposta realizada no questionário online, vide exemplo: $\mathrm{S}_{1}, \mathrm{~S}_{2}$, $\mathrm{S}_{3}$, sucessivamente, que se (auto)identificaram, sendo:

Quadro 1 - (Auto)Identificação dos participantes
\begin{tabular}{|c|c|l|l|l|l|}
\hline Sujeito & $\begin{array}{c}\text { Idade } \\
\text { em anos }\end{array}$ & $\begin{array}{c}\text { Disciplina que mi- } \\
\text { nistra }\end{array}$ & \multicolumn{1}{|c|}{ Formação } & $\begin{array}{c}\text { Tempo de atu- } \\
\text { ação }\end{array}$ & $\begin{array}{c}\text { Participação em } \\
\text { Projeto }\end{array}$ \\
\hline$S_{1}$ & 23 & Ciências e Biologia & $\begin{array}{l}\text { Licenciado em Ciências Biológicas e } \\
\text { Licenciando em Ciências Sociais }\end{array}$ & Não informado & PIBID - Ciências \\
\hline$S_{2}$ & 22 & Ciências & Licenciado em Ciências Biológicas & Não Informado & PIBID - Ciências \\
\hline$S_{3}$ & 55 & Ciências & Licenciado em Ciências Biológicas & 35 anos & PIBID - Ciências \\
\hline$S_{4}$ & 52 & Ciências & Licenciado em Ciências Biológicas & 27 anos & Não informado \\
\hline$S_{5}$ & 30 & Ciências e Física & $\begin{array}{l}\text { Licenciado em Ciências, habilitação } \\
\text { em Física }\end{array}$ & 1 ano & PIBID - Física \\
\hline$S_{6}$ & 22 & Ensino Fundamental I & Licenciado em Pedagogia & 2 anos & PIBID - Pedagogia \\
\hline$S_{7}$ & 28 & $\begin{array}{l}\text { Ciências, Biologia e } \\
\text { Sociologia }\end{array}$ & $\begin{array}{l}\text { Licenciado em Ciências Biológicas e } \\
\text { Ciências Sociais }\end{array}$ & 8 anos & Não Participa \\
\hline$S_{8}$ & 36 & Ciências & Licenciatura em Ciências Biológicas & 12 anos & Não Participa \\
\hline
\end{tabular}

Fonte: Arquivo pessoal

\section{PERCEPTOS MEDIADOS POR PROFESSORES QUE ENSINAM CIÊN- CIAS}

Utilizamos o termo "perceptos” apelando a Gilles Deleuze (2004), considera que os perceptos atuam inseparavelmente dos afectos e dos conceitos. Assim, “[...] Os perceptos não são percepções, são pacotes de sensações e de relações que sobrevivem aqueles que vivenciam” (DELEUZE, 2004, p. 171). Deste modo, consideramos que os rastros que os professores que ensinam ciências deixaram nos encontros com um conjunto de bites que compunham o questionário online, marcam não apenas percepções, não apenas representações, mas sim um transbordamento de sensações, de desejos, de demarcação de potências. Potências que são vistas por Deleuze como tudo aquilo que tem força de devir, de vir-à-ser, de diferenciação constante, de multiplicação de modos de perceptar, de afectar, de conceituar e de existir. Sendo assim, o que são destacados são perceptos que naquele instante deixaram registros, que me afetaram e me possibilitaram este rascunhamento.

Os perceptos aqui citados consistem em registros do que podem os corpos, passíveis de sensações, vivenciarem em suas relações com o mundo, neste caso, em relações com estudantes posicionados em "Transtornos do Espectro Autista”. Assim, as considerações não pretendem pontuar percepções, ou seja, o conjunto de sensações organizadas, mas perceptos, isto é, as potências de sensações que transbordam e nos deixam rastros de transbordamento registrados. Todavia, não negamos que em alguns momentos as considerações possam soar como percepções, ou até mesmo sê-las, dando a impressão de que organizo sensações. Pedimos que, quando esta aparência for ressaltada, que leiam de uma forma outra, que vejam o delineado aqui como um pontuar de sensações que vazaram, que se estratificaram, que se mantêm como superfície de subjetivação e que produzem efeitos sob múltiplos corpos: o do professor, o do estudante identificado em TEA, o dos estudantes participantes na sala, o da comunidade escolar, o dos leitores deste manuscrito, o do próprio escritor deste trabalho, e o de todos os demais corpos que encontrarem-se com este.

No encontro com as discursividades movimentadas pelos oito corpos de professores que ensinam ciências, apresentamos quatro perceptos que transbordam dos encontros dos corpos dos professores em relação aos estudantes identificados em TEA, de modo que as sensações, ao olhar para este corpo, decalcam: a) um corpo destoante em relação a um quadro de 
referência tratado como normalidade, marcado como patologia, e também marcado por ausências e por dificuldades; b) um corpo dissidente, que não se enquadra nos padrões estabelecidos como normais, marcado pela particularidade das sensações de forma intensificada; c) um corpo com uma forma outra de existir, de se relacionar, uma particularidade de acordo com um mundo interno deste corpo; e, finalmente, d) um corpo acompanhado por outro, o da professora de apoio.

Perceptos A - O corpo em TEA como um corpo patológico, de ausências e dificuldades. Transbordes de sensações que ficam mais perceptíveis nos discursos de $\mathrm{S}_{2}, \mathrm{~S}_{3}, \mathrm{~S}_{5}, \mathrm{~S}_{7}$. Perceptos que tratam o enquadramento de corpos em TEA ${ }^{12}$ como corpos doentes, que tiveram problemas de desenvolvimento, nas dificuldades de demonstração de habilidades, na falta de algo que lhes é esperado, discursividades calcadas no discurso da "ausência" de um comportamento supostamente "normal", segundo um quadro de referências vigente nos regimes de verdade.

Nota-se que a associação com as dificuldades vinha claramente calcada de um traço de "transtorno associado ao desenvolvimento [...] o indivíduo nasce com esta condição" $\left(\mathrm{S}_{2}\right)$. Ou seja, vê-se o corpo em TEA como um corpo que tem, no interior de suas moléculas, uma essência que o enquadra como TEA, capaz de gerar transtornos no desenvolvimento deste corpo. No nível molecular, o corpo já foge à normalidade antes mesmo do nascimento. Perceptos que tratam o corpo em TEA como um corpo com ausência e/ou dificuldade de algo, apelam também para o mesmo como um "distúrbio neurológico" $\left(\mathrm{S}_{3}\right)$ e/ou como "sintomas" $\left(\mathrm{S}_{5}\right)$, em uma apelativa para algo que não necessariamente está neste corpo desde seu nascimento, mas que pode se manifestar no corpo, e em seu comportamento, nas diferentes fases de vida. Há um apelo ao discurso médico-biologista, ou seja, a um olhar onde todos os acontecimentos sobre o corpo estão contidos em informações decifráveis pela Biologia do corpo, são essências, são determinadas, podendo manifestar-se ou não, mas sempre calcadas nos processos bioquímicos que engendram o corpo-carne (cf. FOUCAULT, 2015; 1972). Arrisca-se dizer que um olhar biologizante-determinista dos corpos em TEA pode ter sido produzido pelos processos formativos destes sujeitos, de modo que sua formação encontra-se alinhada ao campo de saber "Biologia".

O corpo em TEA, também é tratado como um estado, de modo que o "Estar com esse transtorno significa [...] ter dificuldades de interagir, socializar, isto é, comunicar-se com os pares [...] parecer estar em outro planeta" $\left(\mathrm{S}_{7}\right)$, reconhecendo o corpo em TEA como uma valorativa social, neste caso, sem descartar aspectos médico-biológicos, mas também não os citando no discurso dito, reconhecendo que estes corpos são percebidos sob a óptica de quem olha à medida que diz que estes corpos aparentam "estar em outro planeta". Assim, a apelativa aqui é de um discurso estético-social, ou seja, de como estes corpos em TEA são vistos e interpretados a partir de valores estabelecidos histórica, social e moralmente (cf. NIETZSCHE, 1974). Talvez a apelativa ao discurso voltado às interações sociais e interpretações estéticas seja estabelecida pela influência da segunda formação de $\mathrm{S}_{7}$, voltada às Ciências Sociais.

Neste tocante, o corpo em TEA é relacionado às dificuldades, às ausências e às patologias, e essas dificuldades-ausências são localizadas no âmbito da interação social, intelectual, da atenção e do comportamento. Todavia, aparecem como singularidades a cada um desses sujeitos. Nota-se que $\mathrm{S}_{2}$, por mais que localize o corpo em TEA como um corpo marcado por tal identificação desde seu nascimento, infere que o mesmo "pode resultar em dificuldades",

12 Optou-se pelo uso do termo "corpos em TEA" compreendendo que os corpos são enquadrados em um quadro de referência que os posiciona nesta localização. Assim vê-se que se situa em um estar, um "em”.

PRACS: Revista Eletrônica de Humanidades do Curso de Ciências Sociais da UNIFAP https://periodicos.unifap.br/index.php/pracs ISSN 1984-4352 Macapá, v. 12, n. 1, p. 23-38, jan./jun. 2019 
mostrando, assim, que em um quadro de referências no modo de existir, de acordo com o processo de normalização, estas dificuldades podem nunca surgir. $\mathrm{S}_{3}$ percepta o corpo em TEA como um corpo que sempre tem estas dificuldades, somadas aos comportamentos repetitivos quando "[...] é contrariado ou não entendido", pois estão calcadas em seu "neurológico". Mas, o mesmo reconhece que existe uma pluralidade de modos de ser autista ao narrar que teve dois alunos "[...] que apresentavam características diferentes", pluralidade esta reconhecida também por S6 e S7.

Destarte, estipula-se o corpo em TEA como um corpo que apresenta dificuldades, ausências de habilidades ou um corpo patológico, que expressa sintomas, isto é, realizado de acordo com um quadro de referências que apela a uma delineação de: normalidade e anormalidade, saudável e doente, natural e artificial. Este processo de (a)normalização, (a)naturalização, (não)saúde, e a produção deste quadro de referência, se dá na produção de regimes de verdade (cf. FOUCAULT, 2016; 2015; 1994; 1972), delineiam fronteiras. Nestes perceptos, evidenciase que o corpo em TEA é posicionado na condição de doente-patológico, de anormal, de transtorno. Uma figura paradoxal, que, ao mesmo tempo, é colocada na posição de desvio da norma, assegurando que a normalidade seja estabelecida, em comparação com tal condição; mas também uma perturbadora da norma, de modo que reestabelece dinâmicas, quando estes corpos se chocam com a norma que eles mesmos ajudam a estabelecer, devido à sua relação norma-desvio.

Assim, toda a dificuldade, a ausência ou a consideração sobre a sintomatologia-doença é situada no reverberar de perceptos e também de percepções sob um quadro de referência Ocidental, médico-biologista, que justifica a manutenção destes sujeitos sob esta posição. Todavia, mesmo tomados por sujeitos pontuados com delineações biológicas deterministas ou relações estéticas sociais, são indicados como passíveis de normalização (cf. FOUCAULT, 2016; 2015; 1972).

Perceptos B - O corpo em TEA como um corpo de sensações intensificadas. Os transbordes em que tratam este autismo são vislumbrados sob o olhar de S1. Professor que inicia suas considerações demarcando "Sei muito pouco a respeito do autismo, mas sei que não é uma doença, mas uma condição de sociabilidade" (S1), de modo que as sensações de seu ínfimo conhecimento sobre este modo de existir, reforça, não o enquadramento de corpos em TEA como corpos patológicos, mas sim corpos em que, nas interações com outros corpos, são lidos e classificados segundo uma posição de identificação TEA, via o processo de sociabilidade. Ao estabelecer onde estes corpos em TEA encontram-se localizados realizam-se processos históricos, contingenciais, nos quais esses corpos em TEA são valorados, lidos e enquadrados em determinada posição de sujeito por meio de um quadro de referência.

$\mathrm{S} 1$, ao afirmar que "a pessoa autista se relaciona com as demais de uma forma muito particular", nos mostra que um quadro de referência estabelece uma relação entre a pessoa autista com as "demais". Então, este quadro que estabelece posicionamentos de corpos, sujeições e modos de ser sob uma referência de "normalidade" que se mostra vigente. As sensações, para o corpo em TEA, são sentidas mais intensamente que os "demais", interpretadas com mais particularidade que os "demais", e, devido a isto, os contatos físicos, as comunicações verbais, os olhares diretos incomodam tanto. Todavia, são essas sensações tão intensificadas que vão "muito além do incomodo para os autistas", elas tocam outras sensações, as modulam e propulsam comportamentos e entendimentos outros sobre os modos de ser e estar no mundo.

Esse percepto, que envolve uma sensibilidade intensificada pode ser correlato aos perceptos

PRACS: Revista Eletrônica de Humanidades do Curso de Ciências Sociais da UNIFAP https://periodicos.unifap.br/index.php/pracs ISSN 1984-4352 Macapá, v. 12, n. 1, p. 23-38, jan./jun. 2019 
registrados por Foucault (1972), mais especificamente na episteme produzida na imagem do louco nos ensaios filosóficos da Antiguidade, contexto em que o louco apresentava tamanha sensibilidade que operava como oráculo, como aquele que consegue sentir e conversar com divindades. Todavia, esta episteme vem repleta de outros sentidos, de modo que as relações cotidianas podem gerar incômodos, sobrecarregar o corpo em TEA, deixá-lo incomodado ou com sensações para além do incômodo que ainda são não nomeadas.

Perceptos C - O corpo em TEA como uma forma outra de existir, de se relacionar, uma particularidade com um mundo interno deste corpo. Ranhuras que são deixadas por S6 e S8. Os corpos em TEA, nestes perceptos, têm seus sentidos produzidos nos encontros como corpos com "comportamentos diferentes" (S6), como "formas do indivíduo se relacionar com o mundo a sua volta, de característica orgânica [...] de peculiaridade [...] tudo dependia do momento em que vivia em seu mundo interno" (S8). Nota-se nestes perceptos não uma apelativa a uma ausência ou dificuldade, ou a um excesso em relação a um quadro de referência que vigora em um regime de verdade hegemônico Ocidental, mas sim uma forma outra de ler, de ser, de estar e de interpretar o mundo. Todavia, observam-se duas marcas que me deixaram intrigado: a ideia de característica orgânica e a ideia de um mundo interno.

No que toca a apresentação do corpo em TEA como “de característica orgânica” (S8), duas interpretações desta sensação podem ser decalcadas: um apelo ao discurso médico-biologista e/ou um corpo-organismo como ontologia não moderna.

Se as sensações apontarem a um viés médico-biologista, o mesmo consiste a uma apelação de um modelo estabelecido na Modernidade, como pontua Foucault (2015), de modo que são realizadas investidas para a produção de uma episteme que constrói um corpo dissecado, em uma "verdade absoluta". Há o estabelecimento de uma essência do ser, fixada em mecanismos descritos pelo campo de saber disciplinar da Biologia, sendo ela própria compreendida como disciplina. Neste caso, S6 e S8 operariam por um quadro de referências, mas reiterariam o corpo em TEA como um corpo em um espectro de normalidade, mas que vive de uma forma outra.

Outra possibilidade seria o uso da ideia de "organismo", sob uma leitura de corpo-organismo como uma categoria ontológica outra, não moderna. Um olhar nietzscheano (cf. RAMACCIOT'TI, 2012; ALVARENGA, 2010; NIETZSCHE, 1974; FOUCAULT, 1967), que rejeita a bipartição corpo-sujeito, sociedade-natureza, aparência-verdade, e considera um corpo que se faz, que é parte deste mundo e não separa seu corpo de sua alma. Aqui a organicidade é o estar presente, é uma leitura hermenêutica que olha as relações humanas interseccionando filosofia-fisiologia-psicologia-arte. Desta forma, a organicidade do corpo em TEA é considerar que o corpo que se encontra nesta posição, ao mesmo tempo faz-se nessa posição, ele (trans)cria valores, não sendo um desvio, uma ausência, uma anormalidade, uma exacerbação de uma quadro de referências, mas sim um corpo em TEA por fazer-se em TEA e ser conceptualizado desta forma pelas intersecções perceptos, pelos afectos e pelos conceitos.

A sensação de um corpo que interage com um "mundo interno" também é um ponto que leva a inquietações, pois retoma outras epistemes com novos sentidos: a) a sensação do corpo em TEA, como o louco na Antiguidade, em contato com um outro mundo, metafísico, que este tem o dom de comunicar-se; b) como um louco na Idade Média, que tem um erro em seu aparelho de pensar, uma falha, que leva-o a buscar respostas em um mundo da aparência, das enganações, dos erros; c) como um louco na Modernidade, que transtorna a razão e busca respostas em um mundo outro, que não inteligível e, assim, perigoso, contaminante, doente e, 
que necessita de reformação (cf. FOUCAULT, 1972).

Perceptos D - O corpo em TEA e sua associação com o corpo Professora de Apoio. Os professores S1, S2, S3, S4, S6 demarcam como sensação, o corpo em TEA encontrar-se sempre acompanhado do corpo de uma Professora de Apoio ao processo educacional, mas S5, S7, S8 não citam tal presença. O corpo da professora de apoio vinha como um corpo que "acompanha" o corpo em TEA (S1, S3), que "auxilia no desenvolvimento das tarefas e no aconselhamento de suas condutas [...] chama atenção" (S2), que orienta o corpo do professor, que ensina ciências e alunos "oferecendo mini aulas" sobre TEA e como se comportar frente a corpos em TEA (S4, S6). Neste cenário, nota-se o corpo em TEA sempre acompanhado e este acompanhamento como exercício de um potencial disciplinador do corpo dos professores que ensinam ciências, do corpo dos estudantes em TEA, do corpo dos demais estudantes e do corpo Professora de Apoio.

Assim, nos encontros dos múltiplos corpos no espaço sala de aula, estes se disciplinam uns aos outros. Ressalta-se que a disciplina é um processo produtivo, potencializador de condutas, igualmente capaz de reiterar determinada norma social ditada por um quadro de referências instituído por regimes de verdades que se encontram em vigor, mas que também produzem frestas para a rarefação das normas e negociatas com estas (cf. FOUCAULT, 2016; 2015; 1994). Ressalta-se que esta disciplina vem vigorada por regimes biopolíticos, ou seja, por operações epistêmicas e de poder que validam modos de existência passíveis de serem vividos. Neste sentido, o corpo Professora de Apoio não é qualquer corpo, mas sim um corpo que passa por um regime disciplinar a fim de receber a outorga de ocupar esta posição. Regimes disciplinares que provêm desde uma formação inicial, uma formação continuada via pós-graduação lato sensu ${ }^{13}$, que se torna quesito obrigatório para acompanhamento do corpo em TEA, até processo de seleção.

\section{DISCIPLINAMENTO DOS CORPOS E MODIFICAÇÕES DE CONDUTAS}

Os encontros dos corpos dos professores que ensinam ciências com os corpos em TEA produzem perceptos, afectos e conceitos. Nesse processo de encontros, os corpos se transformam em suas relações, se disciplinam, voltam a si e (re)(des)fazem-se de formas outras. Arrisco compreender este processo nas noções de dispositivo e de modos de subjetivação, descritos em Foucault $(2016 ; 2015 ; 1994 ; 1972)$. O dispositivo em Foucault apresenta considerações discursivas, na medida em que produz saberes, poderes, discursos; e não discursivos, na medida em que estão atrelados a uma complexa rede de práticas para produzir, veicular, consumir e ser consumido em meio a aparatos institucionais e de institucionalização. Os aparatos discursivos e não discursivos do dispositivo incitam produções e revelações constantes sobre si, práticas de confessionalidade que relatam a si, afirmam a si e, ao mesmo tempo, negocia, reverberando ou rarefazendo os discursos que incidem e emanam nos encontros entre os corpos. Assim, o dispositivo tem um caráter pedagógico, de modo que ele sempre ensina algo, atrelado como está a uma eleição de quais discursos são veiculados, em quais espaçostempos e quais quadros de referências serão produzidos. Dessa maneira, os dispositivos, quando atrelados a regimes de verdade, passam a eleger modos de existência que serão

\footnotetext{
13 É estabelecido na Lei de Diretrizes e Bases da Educação Nacional 9.394/1996 que apenas professores licenciados e que possuem pós-graduação lato sensu em temática de educação especial pode acompanhar estudantes com necessidades especiais em seu percurso formativo.
}

PRACS: Revista Eletrônica de Humanidades do Curso de Ciências Sociais da UNIFAP https://periodicos.unifap.br/index.php/pracs ISSN 1984-4352 Macapá, v. 12, n. 1, p. 23-38, jan./jun. 2019 
legitimados como passíveis de serem (ou não) vividos e (des)valorados.

Esta produção do disciplinamento emerge de encontro a práticas de potencializar modos de ser, de existir e de agir. As práticas são, assim, intensificadas a fim de amplificar as produções, maximizar existências e suas interações, gerenciar, portanto, a vida. Sob um olhar foucaultiano (cf. FOUCAULT, 1999; 1994), os modos de disciplinamento estão relacionados com um investimento sobre o manter vivo, sendo esse estar vivo um estar vivendo de acordo com uma normalização. A disciplina normaliza, ao mesmo tempo em que é gestora das vidas.

Ao investigar as movimentações dos professores que ensinam ciências no encontro com corpos em TEA, nos deparamos com discursividades que revelam um investimento em mudanças na dinâmica da aula, a fim de produzir um espaço-prática adequado para o que é valorado como uma "boa aula", e que, ao mesmo tempo, potencialize o aprendizado dos estudantes que apresentam como característica TEA, sem esquecer os demais corpos presentes. Assim, as movimentações do professorado estão atreladas a uma ideia de disciplina mais efetiva que atravesse os corpos em TEA e, assim, uma instauração biopolítica, uma gestão sobre as vidas e os modos de viver, que atravessam o corpo-indivíduo e o corpo-espécie ${ }^{14}$ que encontram-se em TEA.

Percebe-se, assim, modificações no comportamento do professorado que calibra o dispositivo pedagógico escolar. $\mathrm{S}_{1}$ destaca que nos contatos com este corpo em TEA, passa a realizar uma diagnose de sua aula $\left(\mathrm{S}_{5}\right)$, percebendo que "contato visual incomodava ele" e, assim, modificando sua ação docente. Passou a utilizar metáforas para desviar o olhar, pontuando que "então daria aulas para as formiguinhas no chão"; dialogava com a pedagoga sobre como o estudante via a sua aula; procurava saber da vida do estudante no extraclasse. Já $S_{2}$ pontua que passou a usar mais "aulas no laboratório de ciências", mesmo que às vezes o estudante ficasse mais exaltado, mas "não interferia muito e deixava que a professora (de apoio) corrigisse [...] até mesmo que retirasse" do laboratório.

Também buscando melhorias no desenvolvimento da aula, $\mathrm{S}_{3}$ logo de início reconhece não ter formação específica na área, dizendo que "não estudei na Universidade sobre autismo", e, ao reconhecer sua deficiência na informação, buscou informações em outros lugares, buscando leituras bibliográficas, assistir filmes, trocar experiências com colegas e o auxílio da professora de apoio. $S_{3}$ movimenta-se pedagogicamente "conversando com os alunos" que "[...] o auxiliavam" (bem como apontado por $\mathrm{S}_{4}$ ) e passa a trabalhar com "[...] gravuras relacionadas a disciplina, caça-palavras, imagens" e com o laboratório de informática, sendo este último o espaço onde encontrou maior dificuldade, gerando estranhamento, uma vez que não se trata de um espaço do cotidiano do estudante.

$\mathrm{S}_{4}$ registra que seu primeiro contato com o estudante foi peculiar, pois "[...] não estamos acostumados com um certo tipo padrão de comportamento, estamos acostumados a exercer um certo poder de autoridade sobre os alunos normais", destacando que seu eixo de poderautoridade é desterritorializado e "[...] tive que me adaptar" para manter a ordem e o controle sobre o espaço escolar, buscando cursos para melhor compreender e negociar as relações com corpos em TEA. O "espaço escolar foi alterado em virtude do mapeamento do aluno [...] para propiciar ao aluno autista, mobilidade, convivência" ( $S_{7}$ também apresenta esta preocupação com o espaço).

O que se evidencia nestas movimentações discursivas são recortes no que podemos chamar

14 Utilizo deste conceito Foucaultiano, levando em consideração que o discurso médico-biológico classifica os corpos em TEA, instituem-o uma taxonomia, passível de ser diagnosticada e reconhecida: transformam-o em espécie.

PRACS: Revista Eletrônica de Humanidades do Curso de Ciências Sociais da UNIFAP https://periodicos.unifap.br/index.php/pracs ISSN 1984-4352 Macapá, v. 12, n. 1, p. 23-38, jan./jun. 2019 
de uma tecnologia do olhar, ou seja, um modo de olhar para si, de olhar para sua prática e de olhar ao corpo do alunado. Busca-se, então, o suporte epistemológico nos cursos de formação, ou seja, um dispositivo pedagógico que permite outros olhares. Volta-se o olhar para a prática e para a sala de aula de modo mais atento, a fim de diagnosticar os possíveis problemas no percurso da prática pedagógica e calibrar o dispositivo pedagógico para que os corpos em TEA estejam abarcados pelo processo de normalização. E, finalmente, inclina-se à adaptação do espaço, que se torna também uma adequação dos modos de usar aqueles espaços-tempos e, assim, modula as experiencialidades vividas naquele local. Deslocamentos epistêmicos, ópticos e arquitetônicos são vistos em Foucault (2016; 1994) como modos de controle das atividades, distribuição dos corpos e manutenção de uma norma vigente.

$\mathrm{S}_{6}$, ao reconhecer que seus estudantes apresentavam "[...] comportamentos diferentes", passa então a "[...] utilizar do interesse para que gostasse da atividade do dia" na sala de aula, reconhecendo que "[...] algumas vezes deu certo outras não". S 6 busca auxilio de professores especialistas em educação especial e utiliza o esquema de "[...] acordos" para lidar com os corpos em TEA, voltando o seu olhar para que os estudantes sejam "[...] respeitados e compreendidos". A estratégia disciplinar central torna-se, então, jogar com o desejo do estudante, como, por exemplo: "[...] quando levamos o planetário para a sala, este aluno foi o primeiro a ir vê-lo, e dissemos a ele que se ele se sentasse e fizesse as atividades, mais tarde ele poderia ir lá na frente e vê-lo e explicar o que gosta no planetário para seus colegas". S 7 também utiliza estratégias que negociam com os desejos, usando, por exemplo, um seminário sobre insetos como prática pedagógica, pois “[...] como sabia que o aluno com Asperger gostava de insetos”, pôde desenvolver habilidades de oralidade e de socialização do corpo em TEA em sala de aula.

Uma movimentação constante entre os professores é pedir para que os estudantes trabalhem em grupo $\left(\mathrm{S}_{5}, \mathrm{~S}_{7}, \mathrm{~S}_{8}\right)$ na tentativa de desenvolver estratégias de socialização entre eles. Estratégia que opera de formas múltiplas, de modo que o professor "não deixava os alunos escolherem os grupos" $\left(\mathrm{S}_{5}\right)$, "sorteava" $\left(\mathrm{S}_{8}\right)$, ou tentava que os estudantes "escolhessem" $\left(\mathrm{S}_{7}\right)$ de acordo com suas proximidades.

Perceptamos, assim, movimentos pedagógicos outros, tecnologias que atuam de modo a agenciar os desejos e a controlar os prazeres. Movimentos que têm sido realizados há tempos no campo educacional, tornando a prática de normalização uma prática lúdica, prazerosa e laboral. O que é combinado com a estratégia de inclusão em grupos, assim como, a prática dos prazeres e a prática de organização de grupos, tornam-se tentativas de produção de um contrato-senso social. Habilidades voltadas sob um discurso neoliberal de educação são recrutadas para a organização destes modos de organização, de modo que se busca o estabelecimento de comunicação, confissão e prazer. O que se encontra em jogo aqui são os usos dos prazeres e da noção de comunidade (cf. FOUCAULT, 2016).

As movimentações dos professores que ensinam ciências, assim, buscam estabelecer um processo de normalização via disciplinamento dos corpos em TEA de modo mais profícuo. Todavia, nem sempre o processo busca uma inclusão dos corpos à norma, muitas vezes gera, ao contrário, a manutenção da exclusão. Aqui não estamos falando de admitir que uma determinada prática não funcionou adequadamente quando testada, mas sim que determinada movimentação teve pouco investimento na inclusão dos corpos em TEA as normas. Nota-se, por exemplo, que $S_{1}$ destaca uma condição em que havia preparado um experimento demonstrativo para a aula sobre misturas e, ao chegar em sala, o estudante em TEA estava em uma bancada e o experimento seria realizado em outra, assim "Como os estudantes estavam animados fiz com 
eles e infelizmente o aluno autista não pode ver". S2 apresenta uma condição parecida, na qual, em uma aula experimental, o aluno "ficou bem agitado, falando, gritando, cantando" e a professora de apoio teve que retirá-lo da sala. Processos e movimentações negligentes que também são apresentados pelos pais, como o caso citado por $\mathrm{S}_{8}$, no qual uma aluna "[...] por ter uma mãe super protetora ela não pode ir na saída de campo" ao museu, e no caso de $\mathrm{S}_{5}$, que, ao perceber o aluno como possivelmente posicionado em TEA, “[...] consultou a direção" que apontou que o estudante era apenas calado".

Professores que ensinam ciências têm deslocado suas movimentações no espaço escolar a fim de disciplinar também corpos em TEA, todavia, como todo processo de disciplinamento é um processo de normalização (cf. FOUCAULT, 2016, 1994), este necessita de sujeitos reprovados, rejeitados, deixados de fora ou no percurso, para que as margens delineiem os centros. Neste tocante, as investidas de disciplinamento para a instauração de uma biopolítica da inclusão expandem o espaço ocupado pelo corpo-espécie, mas ainda deixa corpos no caminho.

\section{CONSIDERAÇÕES FINAIS}

Evidencia-se na contemporaneidade um apelo para a manutenção e a gestão da vida, um disciplinar que se volta a um deixar viver. Investidas legislativas e educacionais, como o dispositivo da inclusão, vêm inserindo corpos que despontam de um quadro de referências com o intuito de discipliná-los e de passa-los pela esteira da normalização: a instituição escola. Assim, retomamos nossa preocupação ao apresentar considerações acerca de como os deslocamentos gerados nos encontros de corpos de professores que ensinam ciências e corpos em TEA produzem perceptos e movimentos educacionais, a fim de adequar o devir professor a uma posição outra, que consegue também disciplinar os corpos em TEA, incluindo-os.

Os corpos dos professores que ensinam ciências deixam rastros de seus perceptos sobre corpos em TEA, visualizando conjuntos de sensações que dão sentido aos corpos em TEA, como: a) corpos com ausências, dificuldades ou patológicos em relação a um quadro de referências que delineia uma suposta normalidade; b) corpos com excessos e intensidades do sentir em relação a uma suposta normalidade; c) corpos que são modos de viver outros; d) corpos sempre acompanhados de um corpo professor de apoio.

Arriscamos também pontuar movimentações realizadas pelos corpos dos professores que ensinam ciências ao terem contato com corpos em TEA, de modo que se busca: a) epistemes outras, obtendo informações sobre TEA, em palestras, em conversas com professores de educação especial; b) um olhar outro, de modo que se intensifica a prática da vigília na sala de aula, envolvendo o olhar do professor e dos estudantes sobre si, sobre os agires e comportamentos no espaço escolar; c) um olhar outro sob o espaço-tempo, buscando adequações arquitetônicas, que objetivam modular as relações e experiencialidades na sala de aula e na instituição escola; d) desejos outros, gerenciando desejos dos corpos em TEA e procurando uma produção de um sentimento de grupo, que visa estabelecer um contrato social que joga com as relações entre o individual e o coletivo, atreladas a uma lógica neoliberal. Assim, o professor busca ampliar sua abrangência pedagógica, numa tentativa de que mais corpos sejam absorvidos e normalizados na esteira de normalização do espaço-escola. Amplia-se, assim, a disciplina no corpo-indivíduo em TEA e no corpo-espécie, instituindo não apenas modos disciplinares outros, mas modos de existir e de viver outros.

Este é um convite a pensar o sistema educacional, no que se refere às mudanças nas ações

PRACS: Revista Eletrônica de Humanidades do Curso de Ciências Sociais da UNIFAP https://periodicos.unifap.br/index.php/pracs ISSN 1984-4352 Macapá, v. 12, n. 1, p. 23-38, jan./jun. 2019 
pedagógicas que se dão no sentido de normalização dos corpos em TEA (e não somente a estes), tendo em vista a preparação do indivíduo para uma economia neoliberal, e/ou no balizamento de uma efetiva consideração das especificidades e valorização dos múltiplos modos de existência.

Os perceptos que a realização deste manuscrito nos deixam são passos iniciais de como uma disciplina e uma biopolítica diferente, as quais se manifestam nas relações microfísicas do encontro de professores que ensinam ciências e dos corpos em TEA. Todavia, reconhece-se o caráter embrionário e a necessidade de engajamento nas investigações que tocam os deslocamentos epistemológicos, ópticos, espaciais e de vontade-desejo deste trabalho. Deixamos este manuscrito com o impacto semelhante à de um transtorno, ou seja, esperando que este seja inquietante e que, a partir do encontro com este texto, possa-se impulsionar de corpos na busca de investigações outras.

\section{REFERÊNCIAS}

ALVARENGA, R. Nietzsche e o corpo. Estudos Nietzsche, v.1, n.1, p. 423-428, 2010. AMERICAN PSYCHIATRIC ASSOCIATION. Manual diagnóstico e estatístico de transtornos mentais: DSM-5. Trad. Maria Inês Nascimento. 5. ed., Porto Alegre: Artmed, 2014.

CHAER, G.; DINIZ, R.R.P.; RIBEIRO, E.A. A técnica do questionário na pesquisa educacional. Evidência, v.7, n.7, p. 251-266, 2011.

DELEUZE, G. Conversações. Tradução Peter Pál Pelbart. São Paulo: Editora 34, 2004.

FISCHER, R.M.B. Foucault e a análise de discurso em educação. Cadernos de pesquisa, n. 114, p. 197-223, 2001.

FOUCAULT, M. Nietzsche, Freud, Marx. Nietzsche - Cahiers de Royaumont - Philosophie, n. VI, 1967.

Arqueologia do saber. Trad. Luiz Felipe Baeta Neves. 6 ed. Rio de Janeiro: Forense Universitária, 2002.

Em defesa da Sociedade - curso no Collège de France (1975-1976). Trad. Maria Ermantina Galvão. São Paulo: Martins Fontes, 1999.

Vigiar e punir. Trad. Raquel Ramalhete. Petrópolis: Vozes, 1994.

História da loucura na Idade Clássica. Trad. José Teixeira Coelho Netto. São Paulo: Perspectiva, 1972.

Microfísica do Poder. Trad. Roberto Machado. 4. ed. Rio de Janeiro: Paz e Terra, 2016.

História da sexualidade I: a vontade de saber. Trad. Maria Thereza da Costa Albuquerque; J.A. Guilhon Albuquerque. 3 ed. São Paulo: Paz e terra, 2015.

GUNTZEL, F.; OLIVA, I.V.; KRAUSE, C.D. Educação inclusiva e os desafios no Ensino de Ciências. In: Anais do $8^{\circ}$ Salão Internacional de Ensino, Pesquisa e Extensão, Universidade Federal do Pampa, Uruguaiana, 2016.

NIETZSCHE, F. Obras incompletas. São Paulo: Abril Cultural, 1974.

RAMACCIOTTI, B. L. Nietzsche: fisiologia como fio condutor. Estudos Nietzsche, v.3, n. 1, p. 65-90, 2012. 